\title{
More comprehensive forensic genetic marker analyses for accurate human remains identification using massively parallel DNA sequencing
}

Angie D. Ambers ${ }^{1 *}$, Jennifer D. Churchill ${ }^{1}$, Jonathan L. King ${ }^{1}$, Monika Stoljarova ${ }^{1,2}$, Harrell Gill-King ${ }^{3}$, Mourad Assidi ${ }^{4}$, Muhammad Abu-Elmagd ${ }^{4}$, Abdelbaset Buhmeida ${ }^{4}$ and Bruce Budowle ${ }^{1,4^{*}}$

From 3rd International Genomic Medicine Conference

Jeddah, Saudi Arabia. 30 November - 3 December 2015

\begin{abstract}
Background: Although the primary objective of forensic DNA analyses of unidentified human remains is positive identification, cases involving historical or archaeological skeletal remains often lack reference samples for comparison. Massively parallel sequencing (MPS) offers an opportunity to provide biometric data in such cases, and these cases provide valuable data on the feasibility of applying MPS for characterization of modern forensic casework samples. In this study, MPS was used to characterize 140-year-old human skeletal remains discovered at a historical site in Deadwood, South Dakota, United States. The remains were in an unmarked grave and there were no records or other metadata available regarding the identity of the individual. Due to the high throughput of MPS, a variety of biometric markers could be typed using a single sample.
\end{abstract}

Results: Using MPS and suitable forensic genetic markers, more relevant information could be obtained from a limited quantity and quality sample. Results were obtained for 25/26 Y-STRs, 34/34 Y SNPs, 166/166 ancestry-informative SNPs, 24/24 phenotype-informative SNPS, 102/102 human identity SNPs, 27/29 autosomal STRs (plus amelogenin), and 4/8 X-STRs (as well as ten regions of mtDNA). The Y-chromosome (Y-STR, Y-SNP) and mtDNA profiles of the unidentified skeletal remains are consistent with the R1b and $\mathrm{H} 1$ haplogroups, respectively. Both of these haplogroups are the most common haplogroups in Western Europe. Ancestry-informative SNP analysis also supported European ancestry. The genetic results are consistent with anthropological findings that the remains belong to a male of European ancestry (Caucasian). Phenotype-informative SNP data provided strong support that the individual had light red hair and brown eyes.

Conclusions: This study is among the first to genetically characterize historical human remains with forensic genetic marker kits specifically designed for MPS. The outcome demonstrates that substantially more genetic information can be obtained from the same initial quantities of DNA as that of current CE-based analyses.

Keywords: Human skeletal remains, Massively parallel sequencing (MPS), Phenotype-informative SNPS, Y-STRs, Mitochondrial DNA, Ancestry-informative markers (AIMS)

\footnotetext{
* Correspondence: angie.ambers2@unthsc.edu; bruce.budowle@unthsc.edu

${ }^{1}$ Institute of Applied Genetics, Department of Molecular and Medical

Genetics, University of North, Texas Health Science Center, 3500 Camp Bowie

Boulevard, Fort Worth, TX, USA

Full list of author information is available at the end of the article
} 


\section{Background}

The paramount goal of forensic DNA testing of human skeletal remains is identification of the unknown individual. A variety of genetic markers can be used to achieve identification, including highly polymorphic autosomal short tandem repeat (STR) loci and lineage markers [YSTRs, Y chromosome single nucleotide polymorphisms (Y-SNPs), mitochondrial DNA (mtDNA)]. However, reference samples must be available for comparison for these markers to be informative. In mass disasters, missing persons cases, or cases involving historical/archaeological remains, sometimes there are no clues as to the person's potential identity and/or there are no associations made with a reference sample or reference pedigree via a database search [1]. In such scenarios, identification can be difficult or impossible using solely autosomal STRs and lineage markers. However, there are other genetic markers that can extend human identification capabilities, such as analysis of ancestryinformative markers [2-7] and phenotype-informative SNPs [7-11].

Massively parallel sequencing (MPS) of ancestry- and phenotype-informative SNPs, with its expanded capacity for marker typing, offers the ability to develop investigative leads in such cases [12-16]. Thus, more genetic information can be gleaned from a sample without further consumption of often very limited quantity and quality samples. In this study, MPS was used in an effort to help characterize 140-year-old human skeletal remains that were buried in an unmarked grave in Deadwood, South Dakota USA, a famous town of the American Old West.

In 1874, the discovery of gold in the Black Hills of South Dakota set off one of the last great gold rushes in America. In 1876, miners moved to the area and formally established the city of Deadwood, now a U.S. historical landmark. Deadwood's original cemetery, Ingleside, was located near the town's core business district and contained approximately 100 burials (although cemetery records are incomplete and some were buried in unmarked graves). In 1878, the individuals interred there were relocated to the hills above Deadwood, and Mount Moriah Cemetery was established.

In 2012, a set of unidentified human skeletal remains were unearthed by a construction crew in Deadwood's Presidential District, the original site of Ingleside Cemetery [17-19]. South Dakota State archaeologists and historic preservation officials for the City of Deadwood recovered the skeleton from the site (with the exception of one tooth and a few bones from the hands and feet). Anthropological analyses indicated that the remains are consistent with a male of European ancestry (Caucasian) who was 18-24 years of age at the time of death and $65.7-70.7$ inches tall. No indications of the cause of death were evident in the skeletal samples [19-21].
Forensic odontological analyses determined that this unknown individual was a habitual tobacco user and had nine dental fillings (3 gold, 6 tin/amalgam). The latter observation is indicative of some level of affluence/wealth, as most individuals in the late $19^{\text {th }}$ century would simply have had unhealthy teeth extracted $[20,21]$.

In June 2014, the City of Deadwood and the Deadwood Historic Preservation Commission requested that the Institute of Applied Genetics (IAG) conduct DNA testing on the remains to provide some level of identification [18-21]. Given that the remains were in an unmarked grave and no investigative leads existed regarding his identity, Deadwood city officials were interested in the analysis of DNA markers that could help predict the individual's ancestry and external physical traits. Markers chosen for analysis included Y-STRs, Y-SNPs, ancestry-informative SNPs, phenotype-informative SNPs, and mitochondrial DNA (mtDNA). To the best of our knowledge, this study is among the first to genetically characterize historical human remains with forensic genetic marker kits specifically designed for MPS.

\section{Methods}

The practices for minimizing contamination during the analysis of the Deadwood remains were the same contamination controls recommended for archaeological and ancient DNA specimens, including: (a) use of protective suits, gloves, and masks; (b) bleach decontamination and UV-irradiation of work benches and associated equipment; (c) physical removal and/or chemical destruction of contaminant/exogenous DNA on external bone surfaces; (d) extraction of bone samples in a designated low-copy area; (e) PCR amplification in a location that is physically separated from the extraction area; (f) use of appropriate negative controls, reagent blanks, and positive controls; and (g) replicate testing [22-28].

\section{Bone processing and DNA extraction}

The right femur was provided to the IAG for DNA testing (Loan Accession No. 12-0051, South Dakota Archaeological Research Center) (Fig. 1). A portion of the

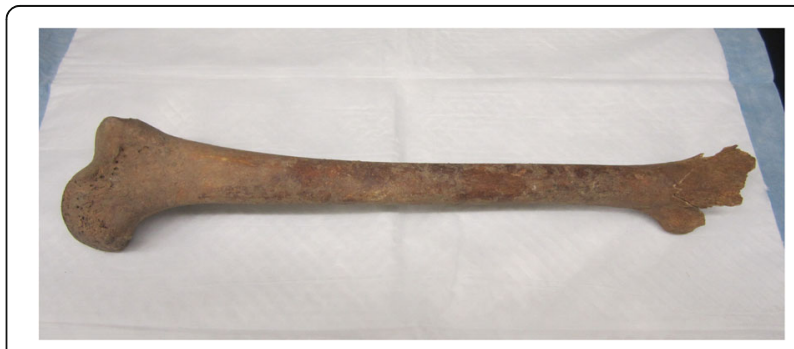

Fig. 1 Right femur of unidentified human skeletal remains discovered in 2012 in Deadwood's Presidential District 
femur diaphysis was surface-sanded with a Dremel $^{\circ}$ 4000 Rotary Tool and sterile grinding stone (Robert Bosch Tool Corporation, Mount Prospect, Illinois USA) followed by sectioning of eight adjacent regions with a Stryker ${ }^{\oplus}$ autopsy saw (Mopec, Oak Park, Michigan USA). DNA extractions were performed on six of the eight bone sections in a designated low-copy number $(\mathrm{LCN})$ area of the laboratory, as described in Ambers et al. [29].

\section{DNA quantification}

The quantity of DNA from seven bone powder fractions was determined using the Quantifiler Human DNA Quantification Kit and an ABI 7500 Real-Time PCR System (Thermo Fisher Scientific, Waltham, Massachusetts USA), according to manufacturers' recommendations [30].

\section{Traditional Y-STR typing via capillary electrophoresis}

Human genomic DNA was amplified with reagents from the AmpFISTR ${ }^{\circ}$ Yfiler $^{\mathrm{rm}}$ PCR Amplification Kit and a GeneAmp ${ }^{\circ}$ PCR System 9700 (Thermo Fisher Scientific), according to manufacturer's recommendations [31]. Negative controls consisted of $10 \mu$ low-TE buffer and $10 \mu \mathrm{l}$ 9947A female DNA $(0.1 \mathrm{ng} / \mu \mathrm{l}) ; 10 \mu \mathrm{l} 007$ Male Control DNA $(0.1 \mathrm{ng} / \mu \mathrm{l})$ served as the positive control. PCR products were separated via capillary electrophoresis (CE) on a $3500 x l$ Genetic Analyzer, and analyzed using GeneMapper ID-X software (Thermo Fisher Scientific). DNA (elution \#1 and elution \#2) from seven bone powder fractions was typed.

\section{Massively Parallel Sequencing (MPS) with the Illumina MiSeq $^{\circledR}$}

DNA from four of the bone powder extracts (007.001 E1, 008.001 E1, 008.002 E1, 008.002 E2) that yielded partial to complete Yfiler $^{\text {Tw }}$ Y-STR profiles was analyzed via MPS. The beta version of the ForenSeq ${ }^{\mathrm{Tm}}$ DNA Signature Prep Kit (Illumina, San Diego, California USA) was used to prepare libraries as described in [32]. For the Illumina ${ }^{\circ}$ ForenSeq DNA Signature Prep Kit, the Y-STR markers analyzed were: DYF387S1, DYS19, DYS385a/b, DYS389I, DYS389II, DYS390, DYS391, DYS392, DYS437, DYS438, DYS439, DYS448, DYS456, DYS460, DYS481, DYS505, DYS522, DYS533, DYS549, DYS570, DYS576, DYS612, DYS635, DYS643, and Y-GATA H4. Input DNA was $0.20 \mathrm{ng}, 1 \mathrm{ng}, 1 \mathrm{ng}$, and $0.58 \mathrm{ng}$, respectively, for the first PCR. Ten microliters of pooled libraries were used for the proceeding "Denature and Dilute Libraries" step. Subsequent sequencing on the MiSeq ${ }^{\circ}$ Desktop Sequencer (Illumina) and data analysis were completed as detailed in [32].
Massively Parallel Sequencing (MPS) with the lon Torrent PGM $^{\oplus}$

DNA from three of the same four bone extracts (008.001 E1, 008.002 E1, 008.002 E2) was analyzed on the Ion Torrent Personal Genome Machine (PGM) platform (Thermo Fisher Scientific). Library preparation, sequencing, and data analysis for three SNP panels [HID-Ion AmpliSeq ${ }^{\text {Tw }}$ Identity Panel, HID-Ion AmpliSeq ${ }^{\text {Tim }}$ Ancestry Panel, and an Externally Visible Characteristics (EVC) prototype panel (Thermo Fisher Scientific)] were completed as described in [33-36]. Input DNA was $1 \mathrm{ng}, 1 \mathrm{ng}$, and $0.58 \mathrm{ng}$, respectively, 22 cycles were used in the initial PCR, and $25 \mu \mathrm{l}$ of pooled libraries were used for preparation of the Ion OneTouch $^{\text {Ts }} 2$ (OT2) amplification solution. Mitochondrial DNA was amplified using an in-house PCR multiplex assay [unpublished]. Eight positions of the mtDNA coding region were sequenced: 4488-4656, 4727-4862, 8542-8707, 10674-10830, 13588-13745, 13809-14098, 14133-14301, and 14766-14923. The noncoding hypervariable regions (HVI, HVII) also were sequenced, as described in [37]. Library preparation, sequencing, and data analysis were completed as outlined in [36] with one exception: $25 \mu \mathrm{l}$ of pooled libraries were used for preparation of the OT2 amplification solution.

\section{Final data analysis}

$30 \mathrm{X}$ and 10X coverage were set as minimum detection thresholds for the autosomal markers and mtDNA typed by MPS in this study, respectively. The $\mathrm{Y}$

Table 1 DNA concentrations (ng/ $\mu$ l) obtained from the right femur of Deadwood's unidentified human skeletal remains (E1 = elution \#1; E2 = elution \#2; total elution volume = $30 \mu \mathrm{l}$ )

\begin{tabular}{lll}
\hline Sample ID & $\mathrm{ng} / \mu \mathrm{l}$ & Total DNA (ng) \\
\hline Femur 001.001 E1 & 0.0327 & 0.98 \\
Femur 001.001 E2 & 0.0082 & 0.24 \\
Femur 002.002 E1 & 0.0232 & 0.70 \\
Femur 002.002 E2 & 0.0029 & 0.09 \\
Femur 003.001 E1 & 0.0147 & 0.44 \\
Femur 003.001 E2 & undetermined & undetermined \\
Femur 006.002 E1 & 0.1730 & 5.19 \\
Femur 006.002 E2 & 0.0147 & 0.44 \\
Femur 007.001 E1 & 0.0383 & 1.15 \\
Femur 007.001 E2 & 0.0014 & 0.04 \\
Femur 008.001 E1 & 0.3080 & 9.24 \\
Femur 008.001 E2 & 0.0347 & 1.04 \\
Femur 008.002 E1 & 0.3350 & 10.05 \\
Femur 008.002 E2 & 0.0579 & 1.74 \\
\hline
\end{tabular}




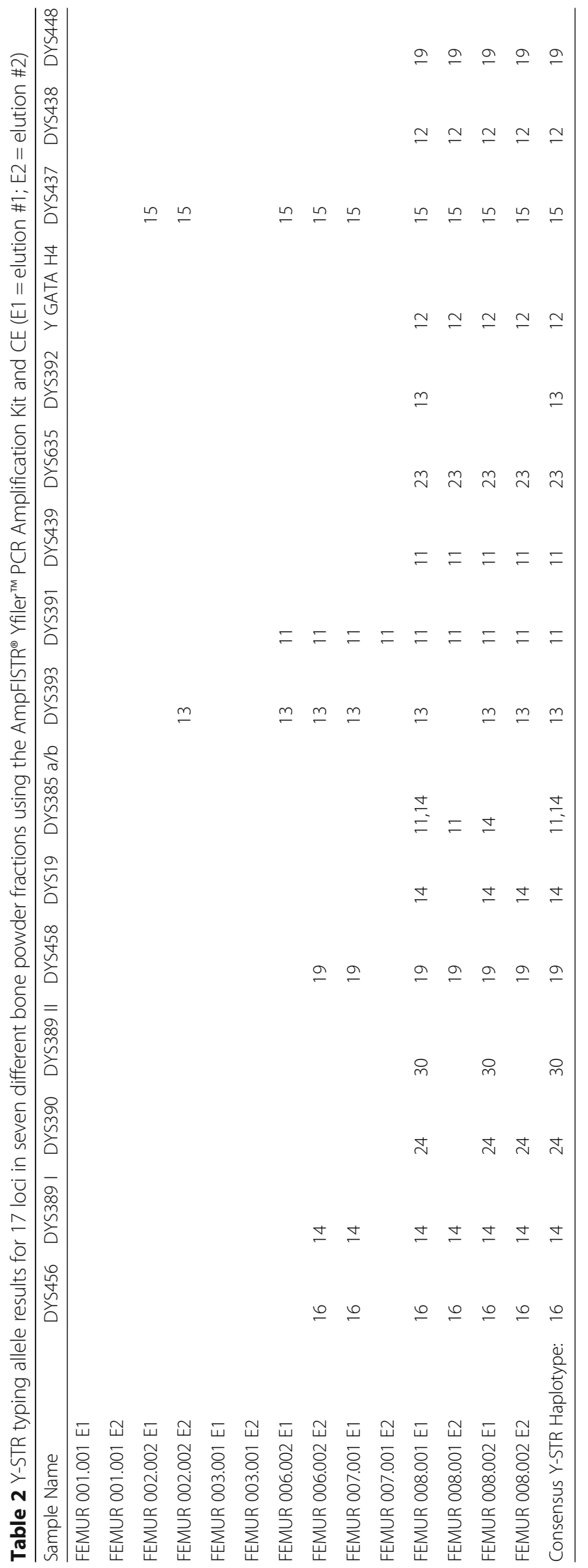


haplogroup was determined using the ancestry feature and metapopulation tool of the Y-STR haplotype reference database YHRD (www.yhrd.org). A PCA plot of ancestry-informative SNP data was generated with the Illumina $^{\circ}$ ForenSeq $^{\text {tm }}$ Universal Analysis Software. Mitochondrial DNA sequence alignment was performed with the mitoSAVE workbook [38], and haplogroup determination was made using HaploGrep software (http://haplogrep.uibk.ac.at/) [39]. Phenotypic SNP data were analyzed with the Illumina ${ }^{\circ}$ ForenSeq ${ }^{\text {Tm }}$ Universal Analysis Software as well as with the HIrisplex hair/eye color prediction tool (http://hirisplex.erasmusmc.nl) $[9,10]$.

\section{Results and discussion}

DNA concentrations recovered from the right femur powder fractions ranged from $0.0147-0.3350 \mathrm{ng} / \mu \mathrm{l}$ for elution \#1 and $0-0.0579 \mathrm{ng} / \mu \mathrm{l}$ for elution \#2, respectively. The elution volume for each DNA extract was $30 \mu \mathrm{l}$, and the total DNA recovered per elution is reported in Table 1.

A variety of STR and SNP markers were analyzed via CE and MPS. No DNA was detected in any of the negative controls and reagent blanks, and positive controls yielded the correct type for all analyses.

\section{Y-chromosome (Y-STR and Y-SNP) DNA Analysis: CE and MPS}

Y-STR typing results varied among the samples (Tables 2 and 3). Allele calls among all extracts were concordant. Individual sample results and the complete 17locus Yfiler $^{\text {Tw }}$ consensus profile are shown in Table 2. Fifteen of the twenty-six Y-STR markers analyzed with the Illumina ${ }^{\circ}$ ForenSeq $^{\text {tix }}$ DNA Signature Prep Kit overlap with the AmpFlSTR ${ }^{\circ}$ Yfiler $^{\text {rn }}$ PCR Amplification Kit. The Y-STR alleles recovered from all bone samples among the common markers between MPS and CE were concordant. Y-STR typing results were obtained for 17 of the 26 markers assayed with MPS (Table 3); coverage ranged from 31x to 620x [148 \pm 137 (Avg \pm $\mathrm{SD})$ ]. The total number of Y-STR loci that yielded results for both methods was 25 .
The composite 17-locus Y-STR profile generated with AmpFlSTR ${ }^{\circ}$ Yfiler $^{\text {Tx }}$ and the additional Y STR loci from the Illumina ${ }^{\circ}$ ForenSeq $^{\text {in }}$ DNA Signature Prep Kit is consistent with the R1b haplogroup. R1b is the most common $\mathrm{Y}$ haplogroup in Western Europe, spanning $80 \%$ of the population in Ireland, western Wales, the Scottish Highlands, the Atlantic fringe of France, Catalonia, and the Basque country. It also is common around the Caucasus and in Anatolia, in parts of Russia, and in Central and South Asia [40-45].

In addition to Y-STR data, a consensus Y-SNP profile was compiled using data from three different bone powder fractions from the Deadwood unidentified skeletal remains. All 34 upper clade Y-SNPs in the HID-Ion AmpliSeq ${ }^{\mathrm{Tm}}$ Identity Panel provided typing results [Additional file 1], and these haplogroupinformative Y-SNP results also supported an R1b haplogroup assignment.

\section{Ancestry informative SNPs}

Ancestry-informative SNP results were obtained for 51 of the 54 SNP markers amplified via the Illumina ${ }^{\circ}$ ForenSeq ${ }^{\text {th }}$ DNA Signature Prep Kit, and for all 165 markers tested using the HID-Ion AmpliSeq ${ }^{\text {Tx }}$ Ancestry Panel. Depth of coverage ranged from $31 x$ to $2240 x$ (170 \pm $107)$ and $53 x$ to $1190 x(379 \pm 243)$, respectively. Fiftythree of the ancestry-informative SNPs in the Illumina ${ }^{\circ}$ ForenSeq $^{\text {tu }}$ kit are included in the HID-Ion AmpliSeq ${ }^{\text {Th }}$ Ancestry Panel, and 51 of these SNPs yielded results with both panels. The results were concordant, and a composite profile was generated [Additional file 2]. Using the ancestry-informative SNP data, the major population bio-ancestry was determined to be European (Fig. 2).

\section{Mitochondrial DNA (mtDNA) Analysis}

An in-house PCR multiplex assay comprised of short amplicons ( 200 bp in length) at targeted sites on the coding and non-coding regions (HVI and HVII) of the mitochondrial DNA (mtDNA) genome was used to characterize the maternal lineage of the Deadwood

Table 3 Y-STR typing allele results for four different bone powder fractions using the Illumina ${ }^{\oplus}$ ForenSeq $^{\text {TM }}$ DNA Signature Prep Kit and MPS (E1 = elution \#1; E2 = elution \#2; markers in common with AmpFISTR ${ }^{\oplus}$ Yfiler $^{\mathrm{TM}}$ are shown in bold)

\begin{tabular}{|c|c|c|c|c|c|c|c|c|c|c|c|c|c|}
\hline Sample Name & DYF387S1 & DYS19 & DYS385a-b & DYS3891 & DYS389|I & DYS390 & DYS391 & DYS392 & DYS437 & DYS438 & DYS439 & DYS448 & DYS456 \\
\hline FEMUR 007.001 E1 & & & & & & & & & & 12 & & & \\
\hline FEMUR 008.001 E1 & & & & 14 & & & 11 & & 15 & 12 & 11 & & \\
\hline FEMUR 008.002 E1 & 36 & & & 14 & & & 11 & & 15 & 12 & 11 & & \\
\hline FEMUR 008.002 E2 & 36 & 14 & & 14 & & & 11 & & & 12 & 11 & 19 & \\
\hline Consensus Y-STR Haplotype & 36 & 14 & & 14 & & & 11 & & 15 & 12 & 11 & 19 & \\
\hline
\end{tabular}


Table 3 Y-STR typing allele results for four different bone powder fractions using the Illumina ${ }^{\circledR}$ ForenSeq ${ }^{\text {TM }}$ DNA Signature Prep Kit and MPS (E1 = elution \#1; E2 = elution \#2; markers in common with AmpFISTR ${ }^{\oplus}$ Yfiler $^{\mathrm{TM}}$ are shown in bold) (Continued)

\begin{tabular}{|c|c|c|c|c|c|c|c|c|c|c|c|c|}
\hline Sample Name & DYS460 & DYS481 & DYS505 & DYS522 & DYS533 & DYS549 & DYS570 & DYS576 & DYS612 & DYS635 & DYS643 & Y-GATA H4 \\
\hline FEMUR 007.001 E1 & & 22 & & & & & & & & & & \\
\hline FEMUR 008.001 E1 & & 22 & 12 & & & & 17 & 17 & & & 10 & \\
\hline FEMUR 008.002 E1 & & 22 & 12 & & & & 17 & 17 & 39 & & 10 & \\
\hline FEMUR 008.002 E2 & & 22 & & 10 & 12 & & & & & 23 & 10 & \\
\hline Consensus Y-STR Haplotype & & 22 & 12 & 10 & 12 & & 17 & 17 & 39 & 23 & 10 & \\
\hline
\end{tabular}

skeletal remains. A total of 10 regions of the mtDNA genome were assayed (HVI, HVII, and eight coding regions covering 2120 bases). The mtDNA regions targeted by the in-house multiplex assay increase discrimination power by $17.4 \%$ beyond sequencing of HV1 and HVII alone (unpublished data). Quality sequencing results were obtained for all 10 regions, with a range in coverage of $19 x$ to $23,987 x$ for $95.3 \%$ of the targeted regions. Nine of the 10 regions sequenced had greater than 1000x coverage (14133-14301 had an average coverage of $\sim 100 x$ ) (Additional file 3 ). No inference of heteroplasmy was observed.

The reportable mtDNA data from these ten regions (2020 bp; 30-305, 4488-4656, 4707-4880, 8520-8726, 10657-10847, 13570-13760, 13791-13990, 1413314301, 14749-14941, 15980-16407) allowed for the following haplotype to be constructed for the reported region (146C, 263G, 4769G, 16181G, 16183C, 16189C). These data provided sufficient genetic information to determine that the most likely mtDNA haplogroup is $\mathrm{H} 1$ with numerous subgroups of $\mathrm{H} 1$ (e.g., H1 + 16189, H1f, H1y, etc.) giving $83.2 \%$ quality score via HaploGrep [39]. Mitochondrial haplogroup $\mathrm{H} 1$ is the most common in Western Europe and is found throughout Europe, northern Africa, the Levant, the Caucasus, Anatolia, and as far as Central Asia and Siberia [46-52]. Hence, the biogeographic ancestry determined by the Y-STR, Y-SNP, ancestryinformative SNP, and mtDNA data are all consistent with that obtained by anthropological analyses of a European ancestry.

\section{Forensic DNA phenotyping}

Twenty-four phenotype-informative SNPs were assayed using the Ion Torrent $\mathrm{PGM}^{\ominus}$ and HID-Ion AmpliSeq Externally Visible Characteristics (EVC) Prototype Panel. Results were obtained for 23 of the 24 phenotype-

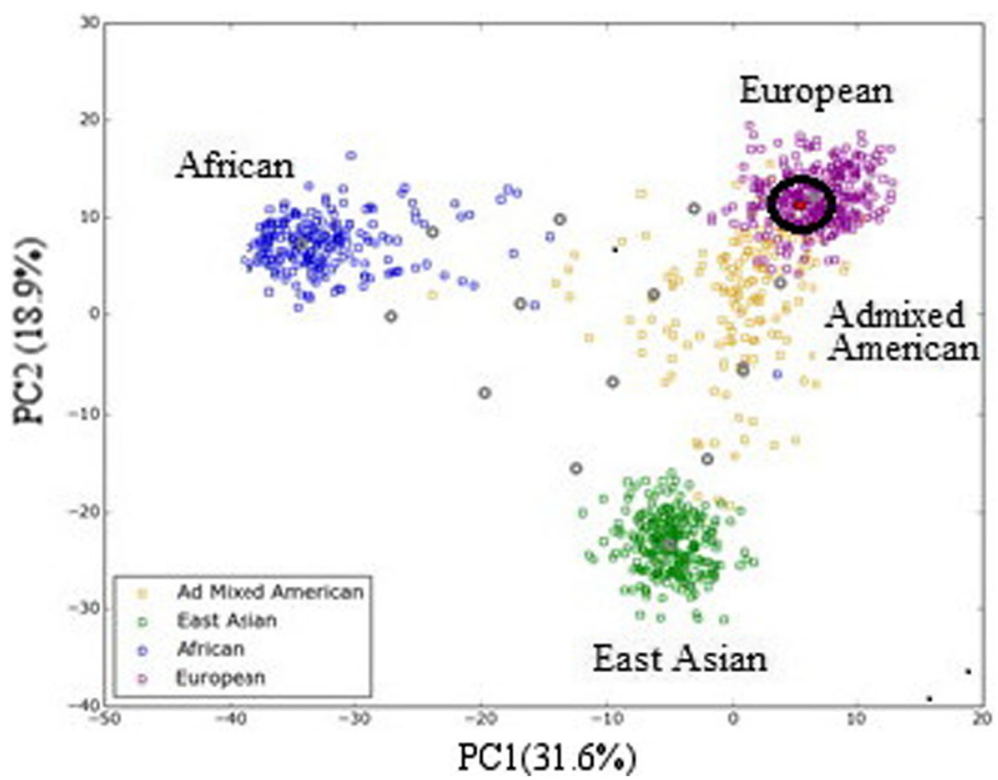

Fig. 2 PCA plot of ancestry-informative SNPs, displaying the best fit population assignment. The population assignment for the 140-year-old unidentified Deadwood skeletal remains is circled in the scatter plot 
informative SNPs assayed, with a depth of coverage of $33 x$ to $1419 x$ ( $282 \pm 205)$ (Table 4$)$.

Additional testing was performed on the skeletal samples using the Illumina ${ }^{\circ}$ ForenSeq $^{\text {tw }}$ DNA Signature Prep Kit and $\mathrm{MiSeq}^{\circ}$ platform. Results were obtained for all 24 phenotype-informative SNP markers assayed, with a depth of coverage of $32 x$ to $1187 x(288 \pm 407)$. Typing results were concordant between assays and between the two MPS platforms. A composite phenotypeinformative SNP profile was generated and is shown in Additional file 4. Phenotypic SNP analysis was performed using the HIrisPlex hair/eye color prediction tool (http://hirisplex.erasmusmc.nl), which generates individual probabilities for four hair color categories (red, blonde, brown, black), two hair color shades (light, dark), and three eye color categories (blue, intermediate, brown) $[9,10]$. The 24 predictive DNA variants (23 SNPs and 1 INDEL) of the HIrisPlex assay are included in the Illumina ${ }^{\circ}$ ForenSeq $^{\text {im }}$ and HID-Ion AmpliSeq $^{\text {tm }}$ Externally Visible Characteristics (EVC) Prototype Panel, and the system was designed to cope with low template and degraded DNA. All 24 DNA variants have small amplicon sizes (< 160 bp). In terms of specificity, HIrisPlex variants provide blue and brown human eye color predictions with over $90 \%$ precision [9] and average hair color prediction accuracies of $0.70,0.79,0.80$, and 0.88 for red, blonde, brown, and black hair, respectively [10]. Analysis of the Deadwood skeletal remains indicated that this individual likely had light red hair and light brown eyes. Probabilities for hair color, hair color shade, and eye color were $0.69,0.71$, and 0.72 , respectively (Table 5).

\section{Other markers assayed with MPS panels}

The Illumina ${ }^{\circ}$ ForenSeq $^{\mathrm{Tm}}$ DNA Signature Prep Kit and the HID-Ion AmpliSeq ${ }^{\text {si }}$ Identity Panel also contain markers that do not contribute to the characterization of bioancestry or phenotype, but nonetheless were able to be typed. With the Illumina ${ }^{\circ}$ ForenSeq $^{\text {mix }}$ DNA Signature Prep Kit, results were obtained for 88/95 human identity SNPs, 27/29 autosomal STRs (plus amelogenin), and 4/8 X-STRs. Range in coverage for the human identity SNPs, autosomal STRs, and X-STRs were $32 x-1085 x(217 \pm 213), 31 x-2838 x(297 \pm 485)$, and $31 x-361 x(170 \pm 107)$, respectively. With the HID-Ion AmpliSeq $^{\text {tw }}$ Identity Panel, results were obtained for 90/ 90 human identity SNPs [Additional files 5, 6 and 7], with a depth of coverage of 33x-1419x (282 \pm 205$)$. There are 80 human identity SNPs in common between the two kits, and 75 of these common markers yielded results with both panels. Results were concordant between the two identity SNP panels. These results further support the potential of MPS to enable typing of a much larger number of genetic markers from the same amount of DNA than would have been possible with current CE-based systems.

\section{Conclusion}

In an effort to learn more about the late- $19^{\text {th }}$-century human skeletal remains discovered at the site of Deadwood's first cemetery, historic preservation officials enlisted a number of forensic specialists to conduct analyses on the remains that could assist in his identification [17-21, 53]. Since the individual was buried in an unmarked grave and no investigative leads existed regarding his identity, lineage testing and forensic DNA phenotyping were performed to predict ancestry and external physical traits.

The Y-chromosome (Y-STR, Y-SNP) and mitochondrial DNA (mtDNA) profiles of the unidentified skeletal remains are consistent with the $\mathrm{R} 1 \mathrm{~b}$ and $\mathrm{H} 1$ haplogroups, respectively. Both of these haplogroups are the most common ones in Western Europe. The ancestry-informative SNPs also indicated a European background. These genetic results are consistent with the findings of a previous anthropological report which determined that the Deadwood unidentified skeletal remains belong to a male of European ancestry (Caucasian). The phenotype-informative SNPs provided strong support that the individual had light red hair and brown eyes. This study is among the first known historical remains case that has been characterized with genetic panels designed specifically

Table 4 Phenotype-informative SNP analysis results for three Deadwood skeletal samples using the lon Torrent PGM ${ }^{\circledR}$ and HID-lon AmpliSeq ${ }^{\text {TM }}$ Externally Visible Characteristics (EVC) Prototype Panel

\begin{tabular}{|c|c|c|c|c|c|c|c|c|c|c|c|}
\hline $\begin{array}{l}\text { Sample } \\
\text { Name }\end{array}$ & rs12896399 & rs28777 & rs1393350 & rs16891982 rs12203592 & N29insA & rs1042602 & rs 2378249 & rs12821256 & rs1800407 & rs12913832 & rs683 \\
\hline $\begin{array}{l}\text { Femur } \\
008.001 \text { E1 }\end{array}$ & $\mathrm{G} / \mathrm{G}$ & A/A & $\mathrm{G} / \mathrm{G}$ & $\mathrm{G} / \mathrm{G}$ & $\mathrm{C} / \mathrm{C}$ & $\mathrm{C} / \mathrm{C}$ & $\mathrm{G} / \mathrm{A}$ & $T / T$ & $\mathrm{G} / \mathrm{G}$ & $A / G$ & $C / A$ \\
\hline $\begin{array}{l}\text { Femur } \\
008.002 \text { E1 }\end{array}$ & $\mathrm{G} / \mathrm{G}$ & A/A & $\mathrm{G} / \mathrm{G}$ & $\mathrm{G} / \mathrm{G}$ & $\mathrm{C} / \mathrm{C}$ & $\mathrm{C} / \mathrm{C}$ & $\mathrm{G} / \mathrm{A}$ & $T / T$ & $\mathrm{G} / \mathrm{G}$ & $A / G$ & $\mathrm{C} / \mathrm{A}$ \\
\hline $\begin{array}{l}\text { Femur } \\
008.002 \text { E2 }\end{array}$ & & $\mathrm{A} / \mathrm{A}$ & $\mathrm{G} / \mathrm{G}$ & $\mathrm{G} / \mathrm{G}$ & $\mathrm{C} / \mathrm{C}$ & & $\mathrm{G} / \mathrm{A}$ & $T / T$ & $\mathrm{G} / \mathrm{G}$ & $A / G$ & $C / A$ \\
\hline
\end{tabular}


Table 4 Phenotype-informative SNP analysis results for three Deadwood skeletal samples using the lon Torrent PGM ${ }^{\circledast}$ and HID-lon AmpliSeq $^{\text {TM }}$ Externally Visible Characteristics (EVC) Prototype Panel (Continued)

\begin{tabular}{|c|c|c|c|c|c|c|c|c|c|c|c|c|}
\hline $\begin{array}{l}\text { Sample } \\
\text { Name }\end{array}$ & rs2402130 & rs4959270 & rs1805005 & rs1805006 & rs2228479 & rs1110400 & rs11547464 & rs1805007 & rs1805008 & rs1805009 & Y152OCH & rs2228479 \\
\hline $\begin{array}{l}\text { Femur } \\
008.001 \\
\text { E1 }\end{array}$ & $\mathrm{A} / \mathrm{A}$ & $C / A$ & $\mathrm{G} / \mathrm{G}$ & $C / C$ & $\mathrm{G} / \mathrm{G}$ & $\mathrm{T} / \mathrm{T}$ & $\mathrm{G} / \mathrm{G}$ & $\mathrm{C} / \mathrm{C}$ & $\mathrm{T} / \mathrm{T}$ & $\mathrm{G} / \mathrm{G}$ & $\mathrm{C} / \mathrm{C}$ & $\mathrm{G} / \mathrm{G}$ \\
\hline $\begin{array}{l}\text { Femur } \\
008.002 \\
\text { E1 }\end{array}$ & $\mathrm{A} / \mathrm{A}$ & $C / A$ & $\mathrm{G} / \mathrm{G}$ & $\mathrm{C} / \mathrm{C}$ & $\mathrm{G} / \mathrm{G}$ & $\mathrm{T} / \mathrm{T}$ & $\mathrm{G} / \mathrm{G}$ & $\mathrm{C} / \mathrm{C}$ & $\mathrm{T} / \mathrm{T}$ & $\mathrm{G} / \mathrm{G}$ & $\mathrm{C} / \mathrm{C}$ & $\mathrm{G} / \mathrm{G}$ \\
\hline $\begin{array}{l}\text { Femur } \\
008.002 \\
\text { E2 }\end{array}$ & $\mathrm{A} / \mathrm{A}$ & $C / A$ & $\mathrm{G} / \mathrm{G}$ & $\mathrm{C} / \mathrm{C}$ & $\mathrm{G} / \mathrm{G}$ & $\mathrm{T} / \mathrm{T}$ & $\mathrm{G} / \mathrm{G}$ & $\mathrm{C} / \mathrm{C}$ & $\mathrm{T} / \mathrm{T}$ & & $\mathrm{C} / \mathrm{C}$ & $\mathrm{G} / \mathrm{G}$ \\
\hline
\end{tabular}

for forensic human identification purposes. The results were highly informative. The study demonstrates the potential of MPS to analyze unidentified human skeletal remains and to provide substantially more genetic information from the same initial quantities of DNA sample as that of CE-based analyses. Using the Illumina ${ }^{\circledR}$ ForenSeq $^{\mathrm{Tm}}$ DNA Signature Prep Kit, results were obtained for 25/26 Y-STRs, 88/95 human identity SNPs, 51/54 ancestry-informative SNPs, 24/24 phenotype-informative SNPs, 27/29 autosomal STRs (plus amelogenin), and 4/8 X-STRs. With the HID-Ion AmpliSeq ${ }^{\mathrm{Tm}}$ Identity Panel, results were obtained for 34/34 Y-SNPs and 90/90 human identity SNPs. The HID-Ion AmpliSeq ${ }^{\mathrm{Tm}}$ Ancestry Panel yielded data for 165/165 ancestry-informative SNP markers assayed. Combined results for all MPS panels included genetic data for 25/26 Y-STRs, 34/ 34 Y SNPs, 166/166 ancestry-informative SNPs, 24/ 24 phenotype-informative SNPs, 102/102 human identity SNPs, 27/29 autosomal STRs (plus amelogenin), and 4/8 X-STRs (as well as ten regions of mtDNA).

An important point about DNA testing of historical or archaeological skeletal remains should be emphasized. Six bone sections/cuttings were taken, and bone powder fractions from each were analyzed. Adjacent bone sections yielded vastly different results in terms of DNA quantity and number of allele calls; some regions of

Table 5 Prediction of Deadwood undentified skeletal remains' potential hair and eye color using phenotype-informative SNP data and the Hlrisplex hair/eye color prediction tool (http://hirisplex. erasmusmc.n//) [10]

\begin{tabular}{llllll}
\hline HAIR COLOR & \multicolumn{3}{l}{ HAIR SHADE } & \multicolumn{2}{l}{ EYE COLOR } \\
\hline Brown & 0.19 & Light & 0.71 & Brown & 0.72 \\
Red & 0.69 & Dark & 0.29 & Intermediate & 0.19 \\
Black & 0.04 & & & Blue & 0.09 \\
Blonde & 0.09 & & & & \\
\hline
\end{tabular}

bone did not yield any DNA, while other areas yielded complete profiles. These findings are consistent with a previous study performed on the 120-year-old skeletal remains of an American Civil War soldier [29], which required testing of multiple bone sections and a consensus testing approach to obtain a complete Y-STR haplotype.

With its capacity for simultaneous analysis of a multitude of different types of DNA markers, MPS technology holds promise for use in the characterization of historical and archaeological remains, and in missing persons cases. In addition, in mass disasters or other types of cases where reference samples are not available/known, genetic markers such as ancestry-informative and phenotype-informative SNPs can provide data for craniofacial reconstructions that could be useful for positive identification.

\section{Additional files}

Additional file 1: Y-SNP data for three different bone powder fractions using the HID-Ion AmpliSeq ${ }^{\text {TM }}$ Identity Panel and the Ion Torrent PGM ${ }^{\circledast}$ MPS platform (E1 = elution \#1; E2 = elution \#2). (XLSX 12 kb)

Additional file 2: Ancestry-informative SNP results for 140-year-old skeletal remains from Deadwood, Dakota using the A) Illumina ${ }^{\circledR}$ ForenSeq $^{\text {TM }}$ panel and B) HID-lon AmpliSeq ${ }^{\text {TM }}$ Ancestry Panel. Concordant results for the 53 ancestry-informative SNPs that were common between the two assays were used to generate a composite AIMS profile (C). (XLSX $20 \mathrm{~kb}$ )

Additional file 3: Sequence results for ten regions of the mtDNA genome using an in-house mtDNA panel (unpublished). The overall coverage ranged from $0-23987 x$. The lowest coverage $(\sim 100 x)$ region (14133-14301) is indicated with black box and arrow. A) 140-year-old skeletal remains, B) reagent blank, and C) positive control. (JPG 136 kb)

Additional file 4: Phenotype-informative SNP analysis results for 140-year-old skeletal remains from Deadwood, Dakota using the: A) Illumina ${ }^{\oplus}$ ForenSeq $^{\text {TM }}$ DNA Signature Prep Kit and B) HID-lon AmpliSeq ${ }^{\text {TM }}$ Externally Visible Characteristics (EVC) Prototype Panel (E1 = elution \#1; E2 = elution \#2). Concordant results were used to generate a composite profile (C). (XLSX $12 \mathrm{~kb})$

Additional file 5: Human identity SNP results for 140-year-old skeletal remains from Deadwood, Dakota using the: A) Illumina ${ }^{\circledR}$ ForenSeq $^{\text {TM }}$ DNA Signature Prep Kit and B) HID-Ion AmpliSeq ${ }^{\text {TM }}$ Identity Panel (E1 = elution $\# 1$; E2 = elution \#2). Eighty of the human identity SNPs were common 
between the two panels (shown in bold). Concordant results were used to generate a composite profile (C). (XLSX $17 \mathrm{~kb}$ )

Additional file 6: Autosomal STR typing results for 140-year-old skeletal remains from Deadwood, Dakota using the Illumina ${ }^{\oplus}$ ForenSeq $^{\text {TM }}$ DNA Signature Prep Kit and MiSeq ${ }^{\oplus}$ MPS platform (E1 = elution \#1; $E 2$ = elution \#2). (XLSX $12 \mathrm{~kb})$

Additional file 7: X-STR typing results for 140-year-old skeletal remains from Deadwood, South Dakota using the Illumina ${ }^{\oplus}$ ForenSeq $^{\text {TM }}$ DNA Signature Prep Kit and MiSeq ${ }^{\oplus}$ MPS platform (E1 = elution \#1; E2 = elution \#2). (XLSX $11 \mathrm{~kb})$

\section{Acknowledgements}

This collaborative project was funded by the Institute of Applied Genetics (IAG) and the City of Deadwood Office of Historic Preservation. The skeletal remains were loaned to the IAG by the South Dakota State Historical Society-Archaeological Research Center (Loan \#218, Accession \#12-0051) for DNA testing. We would like to express our thanks to Deadwood City Archivist Michael Runge and the City of Deadwood's Historic Preservation Officer Kevin Kuchenbecker for their invaluable insights into the historical aspects of the case; South Dakota archaeologist and repository manager Katie Lamie for providing information regarding burial excavation and handling of the remains prior to submission for DNA analyses; and Maiko Takahashi for technical assistance in the laboratory. Reagents for MPS were kindly provided by Illumina and Thermo Fisher Scientific. The opinions, findings, and conclusions or recommendations expressed in this publication are those of the authors and do not necessarily reflect those of the City of Deadwood, the South Dakota State Historical Society-Archaeological Research Center, Illumina, or Thermo Fisher Scientific. Publication charges were paid by the Center of Excellence in Genomic Medicine Research, King Abdulaziz University, Jeddah, Saudi Arabia.

\section{Declarations}

This article has been published as part of BMC Genomics Volume 17 Supplement 9, 2016: Proceedings of the 3rd International Genomic Medicine Conference: genomics. The full contents of the supplement are available online at http://bmcgenomics.biomedcentral.com/articles/supplements/ volume-17-supplement-9.

\section{Availability of data and materials}

All datasets supporting the conclusions of this article are included within the article and its additional files.

\section{Authors' contributions}

ADA was the lead scientist who processed the bones, typed samples, analyzed the data, and prepared the manuscript; JDC and MK generated sequencing data; JLK performed data analyses; H G-K facilitated acquisition of the samples and contributed to the design of the study; $M A, M A-E, A B$, and MA-Q contributed to review of the data and preparation of the manuscript; and BB designed the study, performed data analyses, and contributed to manuscript preparation. All authors read and approved the final manuscript.

\section{Competing interests}

The authors declare that they have no competing interests.

\section{Consent for publication}

Not applicable

\section{Ethics approval and consent to participate}

Not applicable

\section{Author details}

${ }^{1}$ Institute of Applied Genetics, Department of Molecular and Medical Genetics, University of North, Texas Health Science Center, 3500 Camp Bowie Boulevard, Fort Worth, TX, USA. ${ }^{2}$ Institute of Gene Technology, Department of Molecular Diagnostics, Tallinn University of Technology, Akadeemia tee 15A-604, Tallinn 12618, Estonia. ${ }^{3}$ Department of Biological Sciences, Laboratory of Forensic Anthropology, Center for Human Identification, University of North Texas, 1511 W. Sycamore, Denton, TX, USA. ${ }^{4}$ Center of Excellence in Genomic Medicine Research (CEGMR), King Abdulaziz University, Jeddah, Saudi Arabia.
Published: 17 October 2016

\section{References}

1. Lorente JA, Entrala C, Alvarez JC, Lorente M, Villanueva E, Carrasco F, Budowle B. Missing persons identification: genetics at work for society. Science. 2000;290:2257-8.

2. Phillips C, Salas A, Sanchez JJ, Fondevila M, Gomez-Tato A, Alvarez-Dios J, Calaza M, Casares de Cal M, Ballard D, Lareu MV, Carracedo A. Inferrring ancestral origin using a single multiplex assay of ancestry-informative marker SNPs. Forensic Sci Int Genet. 2007;1:273-80.

3. Halder I, Shriver M, Thomas M, Fernandez JR, Frudakis T. A panel of ancestry informative markers for estimating individual biogeographical ancestry and admixture from four continents: utility and application. Human Mut. 2008; 29:648-58.

4. Kidd JR, Friedlaender FR, Speed WC, Pakstis AJ, De La Vega FM, Kidd KK. Analyses of a set of 128 ancestry informative single-nucleotide polymorphisms in a global set of 119 population samples. Invest Genet. 2011;2:1-13.

5. Nievergelt CM, Maihofer AX, Shekhtman T, Libiger O, Wang X, Kidd KK, Kidd JR. Inference of human continental origin and admixture proportions using a highly discriminative ancestry informative 41-SNP panel. Invest Genet. 2013;4:13

6. Kidd KK, Pakstis AJ, Speed WC, Grigorenko EL, Kajuna SLB, Karoma NJ, Kungulilo S, Kim J, Lu R, Odunsi A, Okoofua F, Parnas J, Schulz LO, Zhukova OV, Kidd JR. Developing a SNP panel for forensic identification of individuals. Forensic Sci Int. 2006;164:20-32.

7. Budowle B, van Daal A. Forensically relevant SNP classes. Biotechniques. 2008;44:603-8.

8. Kayser M, Schneider PM. DNA-based prediction of human externally visible characteristics in forensics: Motivations, scientific challenges, and ethical considerations. Forensic Sci Int Genet. 2009:3:154-61.

9. Walsh S, Lindenbergh A, Zuniga SB, Sijen T, de Knijff P, Kayser M, Ballantyne KN. Developmental validation of the IrisPlex system: Determination of blue and brown iris colour for forensic intelligence. Forensic Sci Int Genet. 2011; 5:64-471.

10. Walsh S, Liu F, Wollstein A, Kovatsi L, Ralf A, Kosiniak-Kamysz A, Branicki W, Kayser M. The HrisPlex system for simultaneous prediction of hair and eye color from DNA. Forensic Sci Int Genet. 2013;7:98-115.

11. Draus-Barini J, Walsh S, Pospiech E, Kupiec T, Glab H, Branicki W, Kayser M. Bona fide colour: DNA prediction of human eye and hair colour from ancient and contemporary skeletal remains. Invest Genet. 2013;4:3-15.

12. King J, LaRue BL, Novroski NM, Stoljarova M, Seo SB, Zeng X, Warshauer DH, Davis CP, Parson W, Sajantila A, Budowle B. High-quality and highthroughput massively parallel sequencing of the human mitochondrial genome using the Illumina MiSeq. Forensic Sci Int Genet. 2014;12:128-35.

13. Seo SB, King JL, Warshauer DH, Davis CP, Ge J, Budowle B. Single nucleotide polymorphism typing with massively parallel sequencing for human identification. Int J Leg Med. 2013;127:1079-86.

14. Glenn GC. Field guide to next-generation DNA sequencers. Mol Ecol Res. 2011;11:759-69.

15. Fordyce SL, Mogensen HS, Borsting C, Lagacé RE, Chang CW, Rajagopalan $\mathrm{N}$, et al. Second-generation sequencing of forensic STRs using the lon Torrent ${ }^{\text {TM }}$ HID STR 10-plex and the Ion PGM ${ }^{T \text { M. }}$. Forensic Sci Int Genet. 2015; 14:132-40.

16. Seo S, Zeng X, Assidi M, LaRue B, King J, Sajantila A, Budowle B. High throughput whole mitochondrial genome sequencing by two platforms of massively parallel sequencing. BMC Genomics. 2014;15:P7.

17. Pearson JC. Skeletal remains found in Deadwood yard for second time. In: Rapid City Journal. 2012. http://www.bhpioneer.com/local_news/article_ e4177890-6df5-11e1-aae6-001871e3ce6c.html. Accessed 14 October 2014

18. Griffith T. Deadwood continues to dig for answers in $19^{\text {th }}$ century death. In: Rapid City Journal. 2014. http://rapidcityjournal.com/news/local/deadwoodcontinues-to-dig-for-answers-in-th-century-death/article_ad8af61b-3fb9584c-8187-3dff63bd7c11.html. Accessed 17 January 2015

19. Pearson JC. Skeletal remains headed for DNA testing. In: Black Hills Pioneer. 2014. http://www.bhpioneer.com/local_news/article_2b358b94-c1a1-11e3acb1-001a4bcf887a.html. Accessed 3 March 2015

20. Griffith T. Putting a face on the past: Modern scientists unraveling a historic mystery. In: Rapid City Journal. 2014. http://rapidcityjournal.com/news/local/ 
putting-a-face-on-the-past-modern-scientists-unraveling-a/article_7abe98a8c521-5ba2-966c-edef568bb292.html. Accessed 1 January 2015

21. Griffith T. Scientists unraveling a historic Deadwood mystery. In: The Washington Times. 2014. http://www.washingtontimes.com/news/2014/jul/ 6/scientists-unraveling-a-historic-deadwood-mystery/?page=all. Accessed 17 January 2015

22. Cooper A, Poinar HN. Ancient DNA: Do it right or not at all. Science. 2000; 18:1139-41.

23. Yang DY, Watt K. Contamination controls when preparing archaeological remains for ancient DNA analysis. J Archaeol Sci. 2005;32:331-6.

24. Kemp BM, Smith DG. Use of bleach to eliminate contaminating DNA from the surface of bones and teeth. Forensic Sci Int. 2005;154:53-61.

25. Poinar HN. Criteria of authenticity for DNA from ancient and forensic samples. Int Congr Ser. 2003;1239:575-9.

26. Gilbert MTP, Hansen AJ, Willerslev E, Turner-Walker G, Collins M. Insights into the processes behind the contamination of degraded human teeth and bone samples with exogenous sources of DNA. Int J Osteoarchaeol. 2006; 16:156-64

27. Taberlet P, Griffin S, Goossens B, Questiau S, Manceau V, Escaravage N, Waits $L P$, Bouvet J. Reliable genotyping of samples with very low DNA quantities using PCR. Nucleic Acids Res. 1996;24:3189-94.

28. Cowen S, Debenham P, Dixon A, Kutranov S, Thomson J, Way K. An investigation into the robustness of the consensus method of interpreting low-template DNA profiles. Forensic Sci Int Genet. 2011;5:400-6.

29. Ambers A, Gill-King H, Dirkmaat D, Benjamin R, King J, Budowle B. Autosomal and Y-STR analysis of degraded DNA from the 120-year-old skeletal remains of Ezekiel Harper. Forensic Sci Int Genet. 2014;9:33-41.

30. Applied Biosystems. Quantifiler ${ }^{\circledast}$ human and $Y$ human male DNA quantification kits User Manual. https://tools.lifetechnologies.com/content/ sfs/manuals/cms_041395.pdf

31. Applied Biosystems. AmpF/STR ${ }^{\oplus}$ Yfiler $^{\oplus}$ PCR Amplification Kit User Manual. http://www3.appliedbiosystems.com/cms/groups/applied_markets_support/ documents/generaldocuments/cms_041477.pdf

32. Illumina ForenSeq ${ }^{\text {TM }}$ DNA Signature Prep Guide. 2014. http://support. illumina.com/content/dam/illumina-support/documents/documentation/ chemistry_documentation/forenseq/forenseq-dna-signature-prep-guide15049528-c.pdf

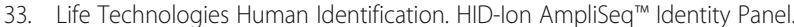
http://www.lifetechnologies.com/content/dam/LifeTech/global/appliedsciences/pdfs/human-identification/CO119694-HID-Ion-AmpliSeq-Identitypanel-Flyer-Americas-FLR.pdf

34. Life Technologies Human Identification. HID-Ion AmpliSeq ${ }^{\mathrm{TM}}$ Ancestry Panel. http://www.lifetechnologies.com/content/dam/LifeTech/global/appliedsciences/pdfs/human-identification/CO117888_Product-Bulletin-HID-IonAmpliSeq-Ancestry-Panel.pdf

35. Life Technologies Human Identification. Ion AmpliSeq ${ }^{\text {TM }}$ Library Preparation for Human Identification Applications. http://tools.lifetechnologies.com/ content/sfs/manuals/MAN0010640_AmpliSeqLibraryPrep_HID_UG.pdf

36. Churchill JD, Chang J, Ge J, Rajagopalan N, Wootton SC, Chang C, Lagace R, Liao W, King JL, Budowle B. Blind study evaluation of the Ion PGM ${ }^{\top M}$ system for use in human identity DNA typing. Croation Med J. 2015;56:218-29.

37. Wilson MR, DiZinno JA, Polanskey D, Replogle J, Budowle B. Validation of mitochondrial DNA sequencing for forensic casework analysis. Int J Legal Med. 1995;108:68-74.

38. King JL, Sajantila A, Budowle B. mitoSAVE: Mitochondrial sequence analysis of variants in Excel. Forensic Sci Int Genet. 2014;12:122-5.

39. Kloss-Brandstatter A, Pacher D, Schonherr S, Weissensteiner H, Binna R, Specht G, et al. HaploGrep: a fast and reliable algorithm for automatic classification of mitochondrial DNA haplogroups. Hum Mutat. 2011;32: $25-32$.

40. Distribution of European Y-chromosome DNA (Y-DNA) haplogroups by percentage. 2015. http://www.eupedia.com/europe/european_y-dna_ haplogroups.shtml. Accessed 3 January 2015.

41. International Society of Genetic Genealogy (ISOGG). Y-DNA haplogroup tree. 2015. http://www.isogg.org/tree/. Accessed 3 January 2015.

42. Y-DNA haplogroups. http://www.worldfamilies.net/yhaplogroups. Accessed 3 January 2015.

43. Y haplogroup prediction from Y-STR values. http://www.hprg.com/hapest5/.

44. International Society of Genetic Genealogy (ISOGG). Y-DNA haplogroup R and its subclades. 2015. http://www.isogg.org/tree/ISOGG_HapgrpR.html. Accessed 3 January 2015.
45. R1b and subclades gateway project for R1b Y-DNA haplogroup. https:// www.familytreedna.com/public/r1b/default.aspx?section=results. Accessed 3 January 2015.

46. The haplogroup $\mathrm{H}$ and $\mathrm{HV}$ mtGenome project: $\mathrm{H} 1 \mathrm{mtDNA}$ distribution map. https://www.familytreedna.com/public/mtdna_h1/default.aspx?section= mtmap. Accessed 3 January 2015.

47. Haplogroup H (mtDNA): Geographic distribution and subclades. http:// www.eupedia.com/europe/Haplogroup_H_mtDNA.shtml\#distribution. Accessed 3 January 2015.

48. Mitochondrial DNA haplogroup mutations. https://www.familytreedna.com/ mtDNA-Haplogroup-Mutations.aspx. Accessed 3 January 2015.

49. International Society of Genetic Genealogy (ISOGG). mtDNA haplogroup H1 and subclades project. 2008. http://www.isogg.org/wiki/MtDNA haplogroup_H1_and_subclades_project. Accessed 2 January 2015.

50. van Oven M, Kayser M. Updated comprehensive phylogenetic tree of global human mitochondrial DNA variation. Hum Mut. 2009;30:E386-94.

51. Mitochondrial DNA (mtDNA) haplogroups. http://www.worldfamilies.net/ mtdnahaplogroups. Accessed 3 January 2015.

52. Roostalu U, Kutuev I, Loogvali EL, Metspalu E, Tambets K, Reidla M, Khusnutdinova EK, Usanga E, Kivisild T, Villems R. Origin and explansion of haplogroup $H$, the dominant human mitochondrial DNA lineage in West Eurasia: The Near Eastern and Caucasian perspective. Mol Biol Evol. 2007;24: 436-48.

53. Pearson JC. Forensic DNA testing of human remains reveals more clues. In: Black Hills Pioneer. 2015. http://www.bhpioneer.com/local_news/article_ c9c84872-92a8-11e4-b71c-5b96b22d2cf9.html. Accessed 15 March 2015

\section{Submit your next manuscript to BioMed Central and we will help you at every step:}

- We accept pre-submission inquiries

- Our selector tool helps you to find the most relevant journal

- We provide round the clock customer support

- Convenient online submission

- Thorough peer review

- Inclusion in PubMed and all major indexing services

- Maximum visibility for your research

Submit your manuscript at www.biomedcentral.com/submit
) Biomed Central 